\title{
ІНФОРМАЦІЙНА ТЕХНОЛОГІЯ ДЕШИФРУВАННЯ АНТРОПОГЕННИХ ЗМІН НА СУПУТНИКОВИХ ЗОБРАЖЕННЯХ
}

Анотація. В роботі запропоновано інформаційну технологію дешифрування антропогенних змін на різночасових супутникових зображеннях високої просторової здатності. Автоматизована технологія включає методи попередньої обробки знімків (підвищення інформативності, корекції), алгоритм уточнення геоприв язки перед пошуком змін на різночасових зображеннях високого просторового розрізнення, який ґрунтується на основі методу SIFT. Результати досліджень свідчать про те, що застосування інформаційної технології дозволяє виявляти антропогенні зміни на різночасових зображеннях.

Ключові слова: супутникове зображення, просторова здатність, дешифрування, антропогенні зміни, інформаційна технологія, різночасові зображення.

Постановка проблеми. В нинішній час існує великий попит на задачі з дешифрування антропогенних змін на поверхні Землі. Ці задачі та запити дуже різноманітні: зміни клімату, грунту, територій водойм, тваринного та рослинного світу, які спричинені діяльністю людини. Будь то прямі чи побічні впливи людської діяльності на природну складову. 3 метою виявлення та вивчення впливу людини на природу проводиться моніторинг довкілля, для визначення впливу людини на навколишнє середовище.

Дані задачі по виявленню змін поверхні Землі можна вирішувати за допомогою різночасових зображень дистанційного зондування земної поверхні. ДЗ3 дозволяє вирішувати широке коло задач в наступних галу3ях:

- картографія;

- визначення змін берегових ліній;

- визначення вирубок лісонасаджень;

(C) Кавац Ю.В., 2019 
«Системні технології» 5 (124) 2019 «System technologies»

- визначення наслідків катастроф природного та техногенного характеру (пожежі, повені, землетруси, урагани, забруднення та ін.);

- визначення незаконних забудов та несанкціонованого заволодіння ділянками землі, тощо.

Через великі витрати часу та потужності на обробку даних дистанційного зондування автоматизація цього процесу набуває актуального значення. Для отримання якісного результату при вирішенні перерахованих задач необхідно мати безхмарні різночасові знімки однієї території з однаковою просторовою здатністю.

Незважаючи на велику кількість різних систем автоматизованого дешифрування і векторизації картографічних зображень, коло вирішуваних ними завдань вельми обмежено. Однією з основних складових інформаційної технології дешифрування змін на різночасових зображеннях $\epsilon$ точна геоприв язка знімків однакової просторової здатності. Як правило такі зображення можуть мати зсув один стосовно іншого на деяку кількість пікселів. Саме тому у випадку виникнення даної проблеми - отриманий результат визначення змін поверхні Землі по декільком різночасовим фотограмметричним зображенням високого просторового розрізнення може бути не дуже якісним та точним. Кожен зміщений піксель інформації буде додавати неточні дані до результату. Тому необхідно розглянути можливість виконати більш точну прив'язку різночасових зображень для отримання коректного та вірного результату.

Основна частина. У роботі пропонується автоматизована інформаційна технологія дешифрування антропогенних змін на різночасових зображеннях високого просторового розрізнення для вирішення прикладних задач, яка реалізована на базі Web - сервісу «EOS Processing» 3 хмарною архітектурою. Web - сервіс призначений для виконання операцій попередньої та тематичної обробки, аналізу супутникових зображень різного просторового розрізнення активних та пасивних сенсорів. Архітектура платформи дозволяє перехід між сервісами без скачування даних на локальні обчислювальні потужності. Сервіс дозволяє працювати з супутниковими зображеннями різного просторового розрізнення, серед яких Sentinel-1, Sentinel-2, Landsat-7, Landsat-8, WorldView-2, WorldView-3, 
«Системні технологіï» 5 (124) 2019 «System technologies»

WorldView-4, RapidEye, SPOT-5, SPOT-6, SPOT-7 Pleiades, KOMPSAT-3, TripleSat та інші. При створенні сесії користувач потрапляє на один із працюючих інстансів кластера, в залежності від того куди його збалансує сервіс. Кожен сервер кластера має свою чергу операцій для виконання і стандартний стек технологій. Однією із прикладних задач, яка може вирішуватися за допомогою Web - сервісу «EOS Processing» є виявлення змін на різночасових зображеннях. Розроблена автоматизована інформаційна технологія дешифрування змін на різночасових зображеннях високого просторового розрізнення. Технологія складається з виконання попередньої обробки знімків (підвищення інформативності, корекції), алгоритму уточнення геоприв язки перед пошуком змін на різночасових зображеннях високого просторового розрізнення, який грунтується на методі Scale Invariant Feature Transform (SIFT). За алгоритмом SIFT спершу знаходяться та зберігаються ключові точки об'єктів на супутниковому зображенні, виконується співставлення ознак та індексація, яка передбачає збереження ключів SIFT і ідентифікацію відповідних ключів із інших зображень. Ключові точки обираються відповідно до їх ступеня стабільності. Етап порівняння та розпізнавання зображень починається із завантаження SIFT-характеристик до бази даних з набору відповідних зображень. На наступному етапі проводиться порівняння характеристик з різних баз даних (різних зображень) та знаходяться спільні характеристики з використанням евклідової метрики. Точки, отримані за допомогою алгоритму, інваріантні до масштабування і поворотів зображення, стійкі до змін освітлення, шумів і змін позиції. Ключові точки на різночасових зображеннях обираються відповідно до їх ступеня стабільності. Ці знайдені дані зберігаються.

Загальна схема автоматизованої інформаційної технології дешифрування антропогенних змін на різночасових зображеннях високого просторового розрізнення представлена на рисунку 1. 
«Системні технології» 5 (124) 2019 «System technologies»

Операції попередньої обробки різночасових зображень

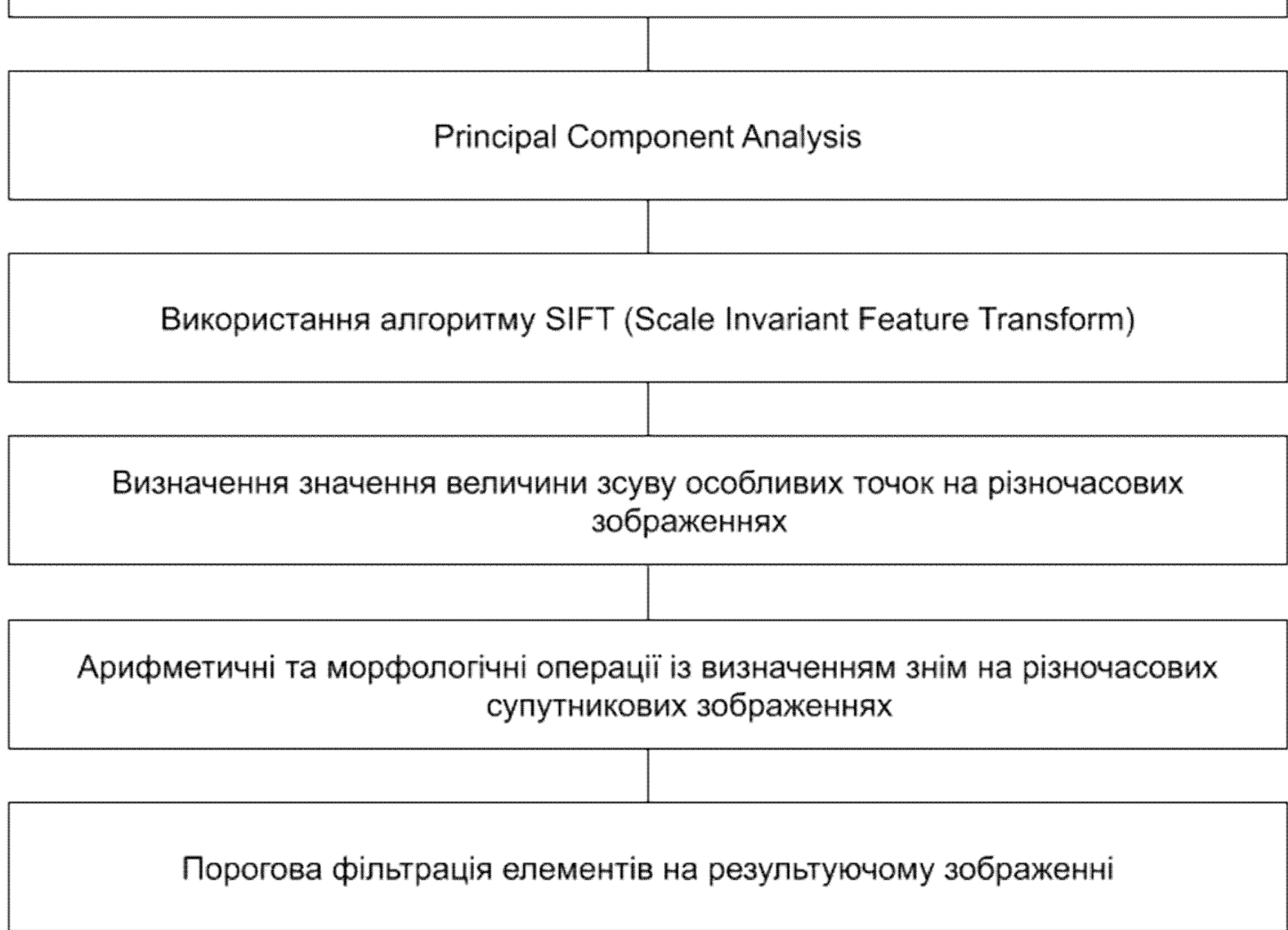

Рисунок 1 - Загальна схема інформаційної технології

Технологія поєднує в собі наступні етапи:

- виконання попередньої обробки знімків (підвищення інформативності [1] на різночасових зображеннях, корекція різночасових зображень);

- виконання над різночасовими фотограмметричними супутниковими зображеннями операції PCA(Principal Component Analysis);

- алгоритм уточнення геоприв язки (перед пошуком змін на різночасових зображеннях високого просторового розрізнення), який грунтується на методі Scale Invariant Feature Transform (SIFT). Алгоритм базується на знаходженні інваріантних властивостей об'єктів, які можливо використовувати для надійного порівняння різних видів об’єктів та сцен. Алгоритм надійно працює з різними масштабами, афінними спотвореннями, з шумами та зображеннями різного освітлення. 
«Системні технологіï» 5 (124) 2019 «System technologies»

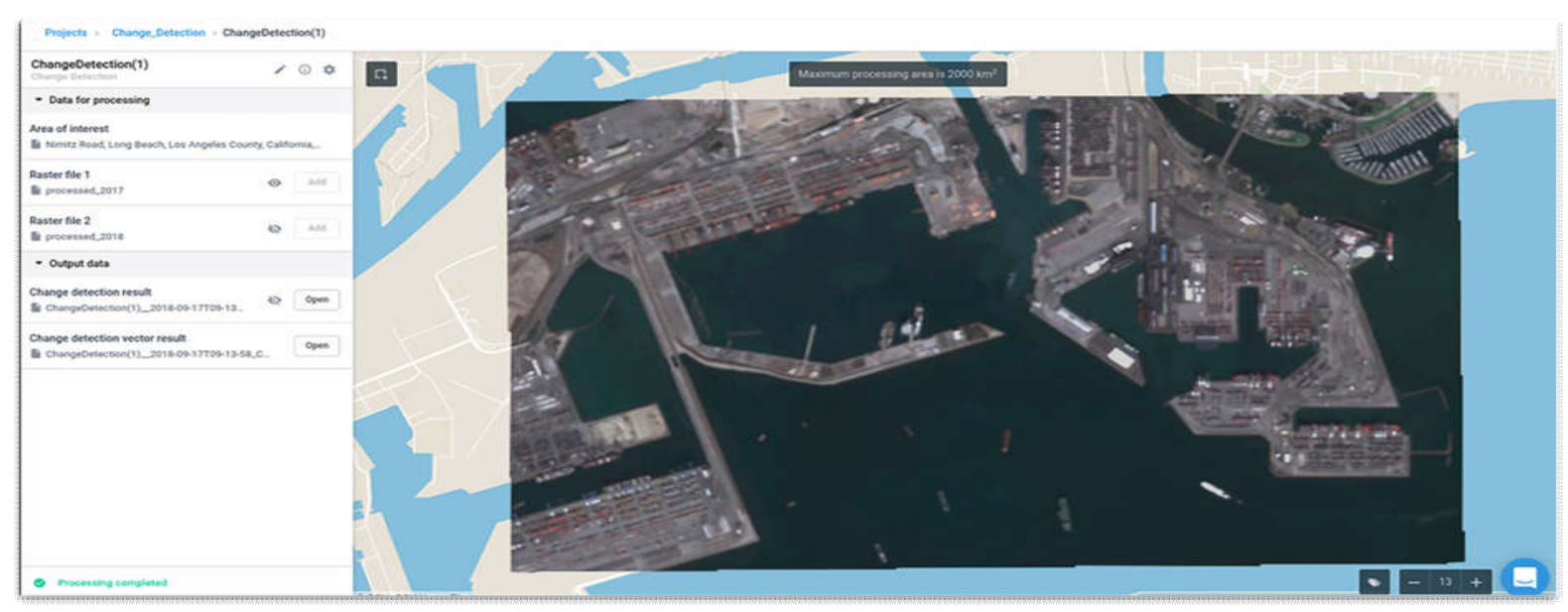

Рисунок 2 - Різночасові супутникові зображення Sentinel-2 території

Long Beach, Los Angeles County, California, United States of America, дата зйомки 15.12.2017

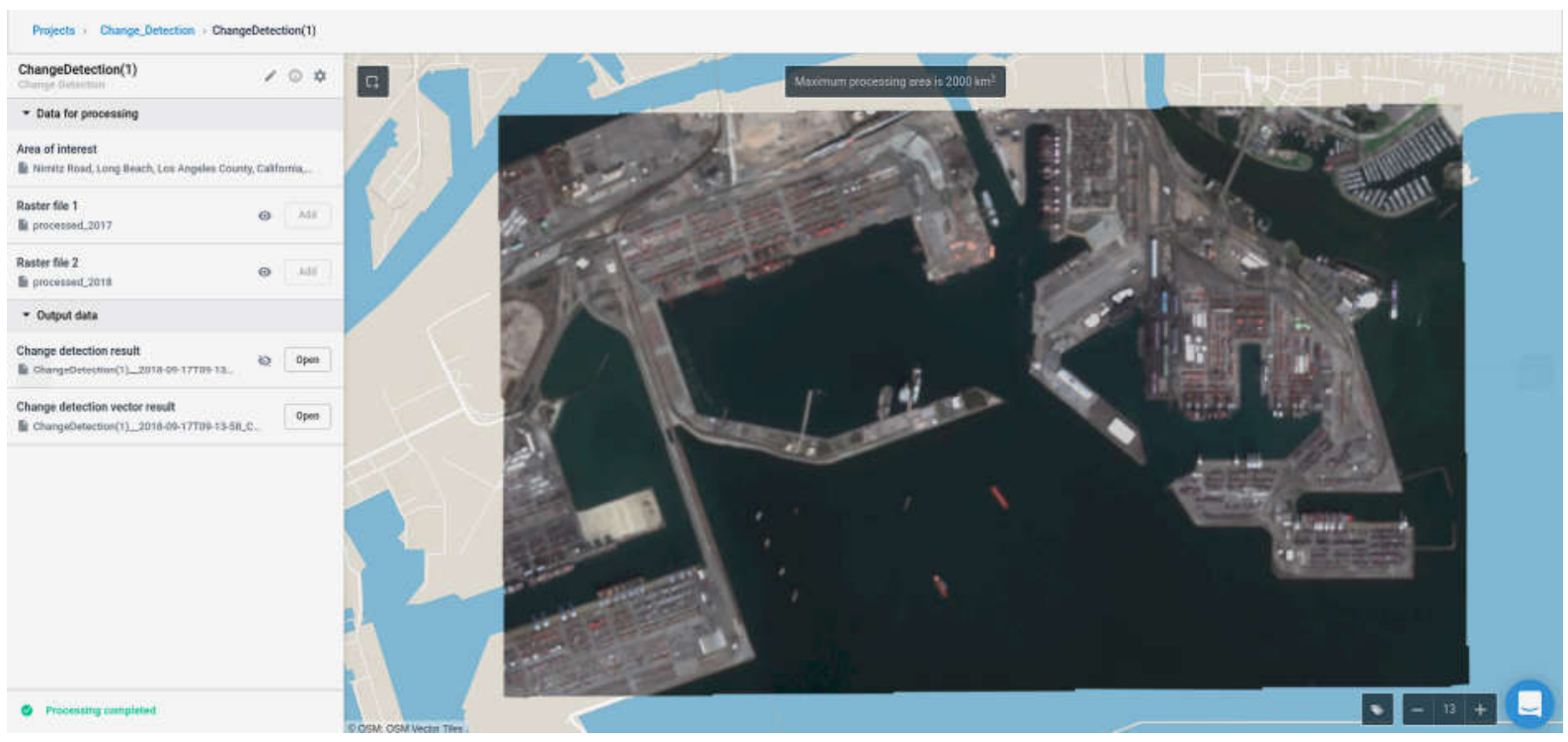

Рисунок 3 - Різночасові супутникові зображення Sentinel-2 території Long Beach, Los Angeles County, California, United States of America, дата зйомки 03.02.2018 


\section{«Системні технологіï» 5 (124) 2019 «System technologies»}

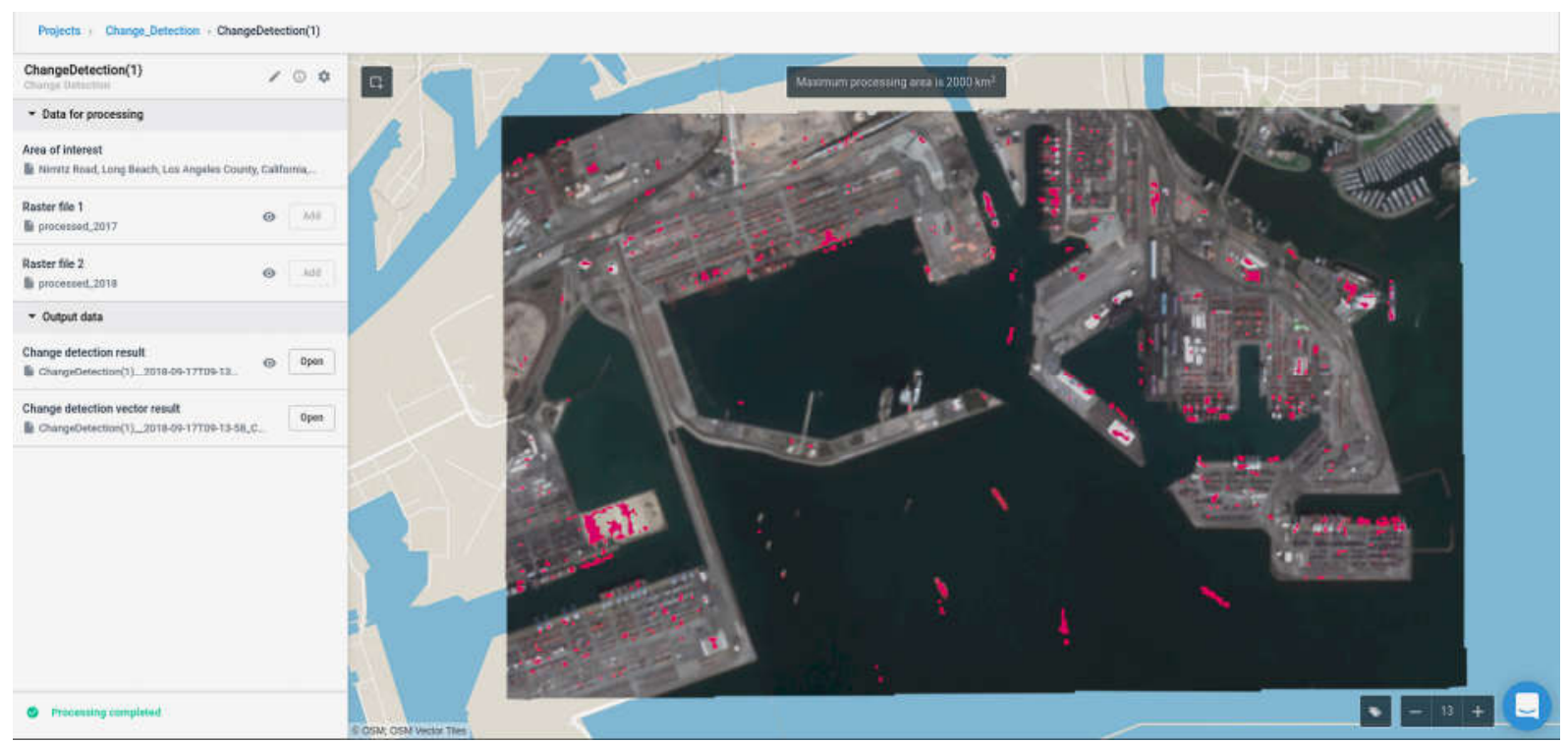

Рисунок 4 - Результат обробки різночасових супутникових зображень

Sentinel-2 території Long Beach, Los Angeles County, California, United

States of America за допомогою Change Detection workflow

продукта EOS Processing

Висновки. Задачі по виявленню антропогенних змін поверхні Землі можна вирішувати за допомогою різночасових зображень дистанційного зондування. У роботі запропонована інформаційна технологія по виявленню антропогенних змін на різночасових супутникових зображеннях. Доведено, що виконання одного із етапів інформаційної технології із застосуванням методу SIFT, який показав стабільну стійкість до вагомих характеристик (інваріантних ключових точок та дескрипторів, масштабування елементів, поворотів зображення, змін освітлення, шумів і змін позиції), дозволяє отримати більш точні результуючі дані при виконанні операції дешифрування антропогенних змін на різночасових фотограмметричних супутникових зображеннях.

\section{ЛИТЕРАТУРА / ЛІТЕРАТУРА}

1. Hnatushenko V.V. Pansharpening technology of high resolution multispectral and panchromatic satellite images / V.V. Hnatushenko, O.O. Kavats, Vik.V.Hnatushenko, V.Ju. Shevchenko // Scientific bulletin of National Mining University. - State Higher Educational Institution "National Mining University”, - Dnipropetrovsk, 2015. - № 4 (148). - C. 91-98.

2. David G. Object Recognition from Local Scale-Invariant Features / Proc. of the International Conference on Computer Vision, Corfu (Sept. 1999) P. 1-8. 3. David G. Lowe Distinctive Image Features from Scale-Invariant Keypoints International Journal of Computer Vision, 2004. 
«Системні технології» 5 (124) 2019 «System technologies»

4. Кавац О.О., Кавац Ю.В. Хмарні обчислення при тематичній обробці багатоспектральних супутникових зображень. Международный научнопрактический форум «НАУКА И БИЗНЕС» г. Днепр.1 июля 2016 г.,С.26-29.

\section{REFERENCES}

1. Hnatushenko V.V. Pansharpening technology of high resolution multispectral and panchromatic satellite images / V.V. Hnatushenko, O.O. Kavats, Vik.V.Hnatushenko, V.Ju. Shevchenko // Scientific bulletin of National Mining University. - State Higher Educational Institution "National Mining University”, - Dnipropetrovsk, 2015. - № 4 (148). - C. 91-98.

2. David G. Object Recognition from Local Scale-Invariant Features / Proc. of the International Conference on Computer Vision, Corfu (Sept. 1999) P. 1-8.

3. David G. Lowe Distinctive Image Features from Scale-Invariant Keypoints International Journal of Computer Vision, 2004.

4. Kavats O.O., Kavats Yu.V. Hmnarny numbered with thematic sampling of ba-gatospectral suputnikovye image. International Scientific and Practical Forum "SCIENCE AND BUSINESS" Dnipro. July 1, 2016, S. 26-29.

\section{Информационная технология дешифрирования антропогенных изменений Accepted 25.10.2019.}

Received 18.10.2019

\section{на спутниковых изображениях}

В работе предложена эффективная информационная технология дешифрирования антропогенных изменений на разновременных спутниковых изображениях. В предлагаемой автоматизированной технологии, производится поэтапное выполнение методов предварительной обработки снимков (повышение информативности, коррекции), алгоритма уточнения геопривязки, перед поиском изменений на разновременных изображениях высокого пространственного разрешения. Тестирование технологии доказало свою высокую эффективность, при обработке ДЗ3 изображений.

Information technology for the detection of anthropogenic changes in satellite images

The paper proposes an effective information technology for the detection of anthropogenic changes in satellite images.

In the proposed, automated technology, a step-by-step implementation of the image preprocessing method (enhancement of information, correction), an algorithm for refinement of geo-binding before searching for changes in high-resolution temporal images, is carried out. Technology testing has proven to be highly effective in processing image imaging.

Кавац Юрий Витальевич - соискатель кафедры информационных технологий и систем Национальной металлургической академии Украины.

Кавац Юрій Віталійович - здобувач кафедри інформаційних технологій та систем Національної металургійної академії України.

Kavats Yuriy Vitalievich - applicant for the department of information technologies and Systems of the National Metallurgical Academy of Ukraine. 